\title{
Produção animal e valor nutritivo da forragem de pastagem de coastcross consorciada com amendoim forrageiro
}

\author{
[Animal production and nutritive value of a coastcross pasture mixed with forage peanut] \\ L.M. Barbero ${ }^{1}$, U. Cecato ${ }^{2}$, S.M.B. Lugão ${ }^{3}$, J.A.N. Gomes ${ }^{2}$, V.A. Limão ${ }^{1}$, \\ J.J.S. Abrahão ${ }^{3}$, C.F.C. Roma ${ }^{2}$ \\ ${ }^{1}$ Escola Superior de Agricultura "Luiz de Queiroz" - USP - Piracicaba, SP \\ ${ }^{2}$ Universidade Estadual de Maringá - Maringa, PR \\ ${ }^{3}$ Instituto Agronômico do Paraná - Paranavaí, PR
}

\begin{abstract}
RESUMO
Neste estudo foram utilizados os tratamentos: coastcross + amendoim forrageiro $+200 \mathrm{~kg} / \mathrm{ha}$ de $\mathrm{N}$; coastcross + amendoim forrageiro $+100 \mathrm{~kg} / \mathrm{ha}$ de $\mathrm{N}$; coastcross $+200 \mathrm{~kg} / \mathrm{ha}$ de $\mathrm{N}$ e coastcross + amendoim forrageiro (parcelas) no inverno, primavera, verão e outono (sub parcelas), delineados em blocos ao acaso. Novilhas foram manejadas sob lotação contínua e taxa de lotação variável em pastagem mantida a $17 \mathrm{~cm}$ de altura. Amostras foram coletadas a cada 28 dias para determinar o valor nutritivo da forragem. Foram avaliados: ganho médio diário (GMD), ganho de peso vivo (GPV), taxa de lotação (TL) e número de animais dia (NAD). Quanto ao valor nutritivo da forragem, os piores resultados ocorreram nas pastagens sem adubação, 16,9\% e 6,0\% de PB de folha e colmo, respectivamente, e 70,1\% de FDN de folha. Na primavera e no verão, o GMD foi mais alto, 0,518 e 0,515kg/animal do que no inverno e outono, 0,396 e 0,293kg/animal, respectivamente. A TL foi superior nas pastagens que receberam a maior dose de nitrogênio, 5,38UA/ha em média, e no verão, 6,81UA/ha. O GPV foi mais elevado nas áreas com adubação, $1341 \mathrm{~kg}$ de PV/ha, em relação aos pastos não adubados, $735 \mathrm{~kg} / \mathrm{ha}$.
\end{abstract}

Palavras-chave: bovino de corte, desempenho animal, leguminosa, produção de carne

\begin{abstract}
In this study, the following treatments were used: coastcross + forage peanut $+200 \mathrm{~kg} / \mathrm{ha}$ of $\mathrm{N}$; coastcross + forage peanut $+100 \mathrm{~kg} / \mathrm{ha}$ of $\mathrm{N}$; coastcross $+200 \mathrm{~kg} / \mathrm{ha}$ of $\mathrm{N}$ and coastcross + forage peanut (plots) in the winter, spring, summer, and autumn (subplots), designed in randomized blocks. Heifers were managed under continuous stocking and variable stocking rate on pasture maintained at $17 \mathrm{~cm}$ height. Samples were collected every 28 days determining the nutritional value of forage. Average daily gain (ADG), weight gain (WG), stocking rate (SR), and number of animals/day (NAD) were evaluated. As for forage nutritional value, the worst results were found in pasture without fertilization, $16.9 \%$ and $6.0 \%$ CP of leaf and stem, respectively, and $70.1 \%$ NDF in leaves. In the spring and summer, animals had a higher ADG, 0.518 and $0.515 \mathrm{~kg} /$ animal, than 0.396 and $0.293 \mathrm{~kg} /$ animal in the winter and autumn, respectively. SR was higher in pastures that received higher nitrogen doses, 5.38AU/ha in average; and in the summer, 6.81AU/ha. LWG was higher in fertilized areas, 1,341kg LW/ha, than in not fertilized pastures, $735 \mathrm{~kg} / \mathrm{ha}$.
\end{abstract}

Keywords: beef cattle, animal performance, leguminous, meat production

Recebido em 2 de março de 2009

Aceito em 30 de abril de 2010

E-mail: lbarbero@esalq.usp.br

Apoio: Fundação Araucária e IAPAR 


\section{INTRODUÇÃO}

A produção de bovinos de corte criados exclusivamente em pastagens é uma alternativa extremamente viável para que o sistema de produção seja rentável economicamente. As pastagens tropicais, apesar de não oferecerem forragem de elevado valor nutritivo, se comparadas com as de clima temperado, apresentam elevada produtividade de forragem, o que possibilita o uso de taxa de lotação elevada e proporciona satisfatório ganho por área.

As gramíneas do gênero Cynodon, em razão das vantagens nutricionais, do potencial produtivo, da resposta à fertilização, da adaptação a diferentes ambientes e da flexibilidade de uso, estão sendo intensivamente pesquisadas e utilizadas no Brasil (Vilela et al., 2006). Dentre elas destaca-se a coastcross (Cynodon dactylon [L] Pers $\mathrm{Cv}$ coastcross), que é uma forrageira oriunda de duas variedades de Cynodon dactylon cv. Coastal e uma introdução de bermuda de alta digestibilidade. É um híbrido que tem uma boa resposta à adubação, principalmente ao nitrogênio, e é muito produtivo (Brennecke, 2002).

Um fator importante que determina o potencial produtivo e o valor nutritivo de uma forrageira é a adubação no sistema e o quanto, como e o que é utilizado. O nitrogênio melhora o crescimento e a produção da planta, promove rápido crescimento, aumenta a participação de folhas, melhora a qualidade destas, aumenta o teor de proteínas, e alimenta os microrganismos do solo que decompõem a matéria orgânica (Malavolta, 1980). Contudo, o emprego de altas doses de $\mathrm{N}$ em pastagens, além de elevar os custos de produção, pode ocasionar contaminação do meio ambiente. Assim, o uso de leguminosas consorciadas com gramíneas tropicais pode ser uma alternativa para o suprimento de $\mathrm{N}$ no sistema, pois usa um produto natural e de baixo custo.

Entre as leguminosas forrageiras tropicais, o amendoim forrageiro (Arachis pintoi) vem se destacando e tem permanecido de forma estável, consorciado com gramíneas de comportamento vegetativo agressivo sob pastejo intenso, durante períodos superiores a 10 anos, aumentando, inclusive, a produtividade, se comparados às gramíneas solteiras (Perez e Pizzarro, 2006). A cultivar comercial Arachis pintoi cv. Amarillo, em condições de pastejo consorciado com Brachiaria, produziu $643 \mathrm{~kg}$ de $\mathrm{PV} / \mathrm{ha} / \mathrm{ano}$, e é apontada como uma leguminosa produtiva e resistente ao pastejo e ao pisoteio (Grof, 1985), pois seus pontos de crescimento localizam-se próximo ao nível do solo, dificultando sua remoção pelo ato do pastejo dos animais.

O presente estudo teve o objetivo de determinar o valor nutritivo da forragem e a produção animal em pastagem de coastcross consorciada com amendoim forrageiro, com ou sem adubação nitrogenada, submetida a pastejo com lotação continua.

\section{MATERIAL E MÉTODOS}

O experimento foi realizado na Estação Experimental do IAPAR, em Paranavaí, PR. O tipo climático predominante na região é o cfa clima subtropical úmido mesotérmico pela classificação de Köeppen (Instituto..., 1994). As condições climáticas durante o período experimental são apresentadas na Fig. 1.

O solo da área experimental, originado do Arenito Caiuá, classificado como latossolo amarelo distrófico (Santos et al., 1999), apresenta $88 \%$ de areia, $2 \%$ de silte e $10 \%$ de argila, com baixo $\mathrm{pH}$, baixa capacidade de troca catiônica (CTC), baixo teor de matéria orgânica e de fósforo (Instituto..., 1999).

As avaliações do presente experimento compreenderam o período de 1 de julho de 2006 a 30 de junho de 2007, em uma área já estabelecida com o coastcross consorciado com o amendoim forrageiro, equivalente a 5,3ha, que recebia o mesmo manejo empregado no experimento por um período anterior de cinco anos. Foi utilizado um delineamento experimental de blocos ao acaso e em parcelas subdivididas, com duas repetições, e composto por quatro tratamentos: CA200 - coastcross + amendoim forrageiro $+200 \mathrm{~kg} / \mathrm{ha}$ de N; CA100 coastcross + amendoim forrageiro $+100 \mathrm{~kg} / \mathrm{ha}$ de $\mathrm{N}$ ); C200 - coastcross $+200 \mathrm{~kg} / \mathrm{ha}$ de $\mathrm{N}$; CA coastcross + amendoim forrageiro. As subparcelas corresponderam às estações do ano: inverno, primavera, verão e outono. 


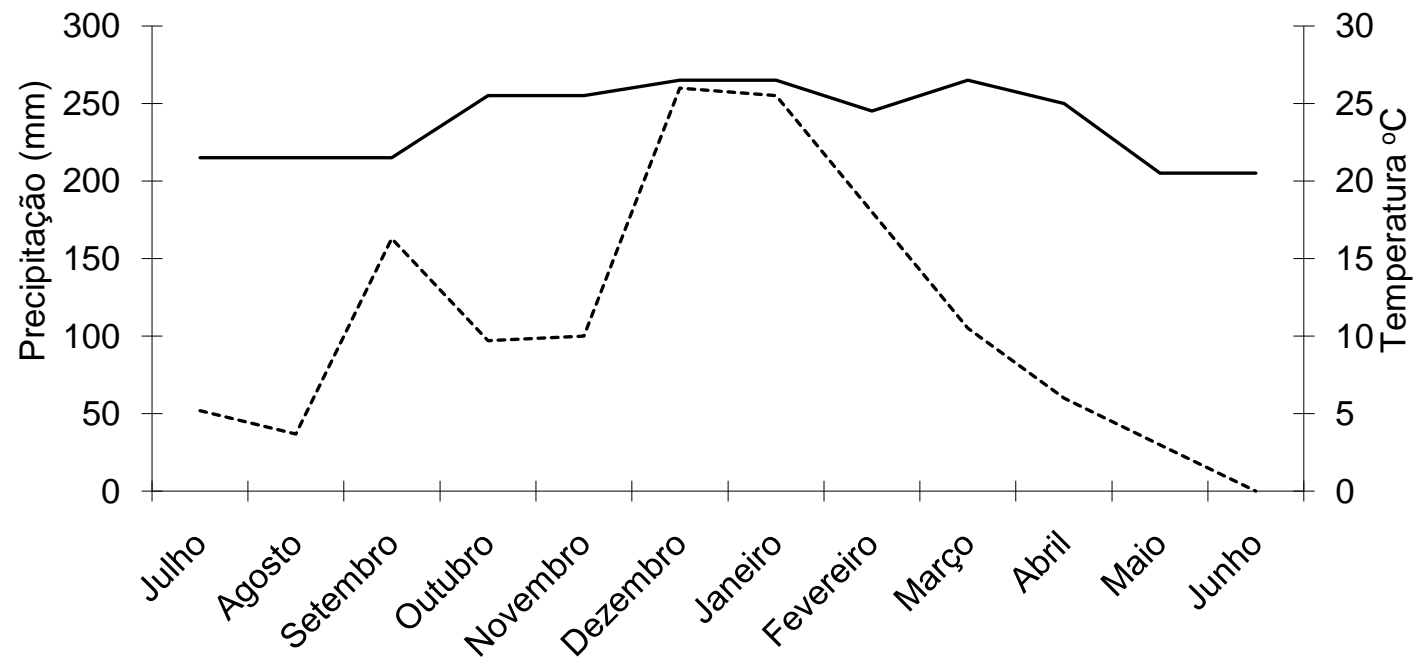

Figura 1. Condições climáticas durante o período experimental de julho de 2006 a junho de 2007.

As aplicações do nitrogênio, tendo como fonte o nitrato de amônio, foram parceladas em quatro vezes: 08/11/06, 28/12/06, 30/01/07 e 05/03/07. Juntamente com a primeira adubação nitrogenada, foi realizada a adubação fosfatada, tendo como fonte o superfosfato simples, com o objetivo de elevar o teor de fósforo a $15 \mathrm{ppm}$. Também foi realizada adubação com micronutrientes com o adubo comercial FTE BR 12 , na dose de $50 \mathrm{~kg} / \mathrm{ha}$. A adubação potássica foi parcelada junto com a nitrogenada, usando-se o cloreto de potássio como fonte com a finalidade de elevar a saturação de K a $4 \%$ da CTC. Toda a adubação foi realizada a lanço, sempre após uma precipitação mínima de $30 \mathrm{~mm}$.

A pastagem foi manejada sob lotação contínua com taxa de lotação variável, onde, duas vezes por semana, foram tomados 50 pontos aleatórios de altura do pasto por unidade experimental. A altura da pastagem foi mantida a $17 \mathrm{~cm}$, com auxílio da técnica do put and take, proposta por Mott e Lucas (1952), colocando ou retirando animais quando a pastagem aumentava ou diminuía em um centímetro em relação à altura média, respectivamente.

Para as avaliações, amostras de forragem, coletadas a cada 28 dias, foram separadas em lâmina foliar (LF) e bainha+colmo (BC) de coastcross e planta inteira de amendoim forrageiro (AF). Após a separação botânica, o material foi seco em estufa de circulação de ar a $55^{\circ} \mathrm{C}$ por 72 horas, até peso constante, foi moído em moinho com peneira de $1 \mathrm{~mm}$ para determinação dos teores de proteína bruta (PB), pelo método micro Kjeldhal (Official..., 1990) e de fibra em detergente neutro (FDN), pelo método de partição de fibras proposto por Van Soest et al. (1991), e de digestibilidade in vitro da matéria seca (DIVMS), de acordo com a metodologia de Tylley e Terry (1963), adaptada para a utilização do rúmen artificial, desenvolvida por Ankon $\AA$, conforme descrito por Garman et al. (1997).

$\mathrm{Na}$ avaliação animal, foram utilizadas três novilhas testers por unidade experimental, com padrão racial predominante Red angus x Nelore e Limousin $x$ Nelore e com idade inicial de oito meses e média de peso vivo de $170 \mathrm{~kg}$. As pesagens ocorreram a cada 28 dias, entre 8 e $9 \mathrm{~h}$, de acordo com a metodologia descrita por Hughes (1976). Com os dados obtidos das pesagens dos animais, calcularam-se o ganho de peso vivo (GPV), o ganho médio diário (GMD), a taxa de lotação (TL) e o número de animais dia (NAD). 
A partir do GMD, foi calculado o GPV ( $\mathrm{kg} / \mathrm{ha}$ ) multiplicando-se o GMD dos testers pelo NAD para cada estação. A TL (UA/ha) foi calculada a partir do peso médio dos reguladores somado aos testers, multiplicando-se pelo número de dias em que eles permaneceram na pastagem, divididos pelo número de dias do período.

As variáveis estudadas foram analisadas por meio do programa estatístico SAS/1999. As médias foram comparadas utilizando-se o teste Tukey.

\section{RESULTADOS E DISCUSSÃO}

Os valores de $\mathrm{PB}$ da fração lâmina foliar $(\mathrm{PBF}) \mathrm{e}$ da fração colmo+bainha (PBC) podem ser visualizados na Tab. 1. Observa-se que durante o ano a pastagem que não recebia adubação nitrogenada teve os menores valores tanto de PBF quanto de PBC. Ainda, pode se verificar que os pastos que receberam a dose de $100 \mathrm{~kg}$ de
N/ha/ano tiveram teores intermediários de PBF quando comparados aos submetidos às outras doses de $\mathrm{N}$, dando ênfase ao efeito do $\mathrm{N}$ vindo da fertilização química no teor de PB da gramínea, onde uma elevada emissão de folhas novas, proporcionada pelo suprimento de $\mathrm{N}$ no sistema, contribui para esse aumento nos teores de PB.

Para a PBF, não houve diferença entre as épocas do ano, mostrando que a constante remoção a que era submetida à gramínea, por ser manejada no método de pastejo com lotação contínua e mantida em uma altura constante, foi recompensada com a formação de folhas novas, mesmo nas épocas do inverno e outono. A diferença para a PBC deve-se ao fato de os colmos nas épocas de inverno e outono serem pouco pastejados, pois os animais têm o hábito de selecionar o alimento que ingerem, com isso os colmos ficam velhos, diluindo o conteúdo de PB (Van Soest, 1994).

Tabela 1. Proteína bruta das frações lâmina foliar $(\mathrm{PBF})$ e bainha+colmo (PBC) da pastagem de coastcross consorciada com amendoim forrageiro, adubadas ou não com $\mathrm{N}$

\begin{tabular}{|c|c|c|c|c|c|c|}
\hline \multirow{2}{*}{ Estação } & CA200 & CA100 & C200 & CA & \multirow{2}{*}{ Média } & \multirow{2}{*}{$\mathrm{CV}(\%)$} \\
\hline & \multicolumn{4}{|c|}{ PBF (\%) } & & \\
\hline Inverno & 20,08 & 19,17 & 19,2 & 16,94 & 18,85 & 10,75 \\
\hline Primavera & 20,50 & 17,77 & 20,96 & 14,80 & 18,51 & 11,74 \\
\hline Verãor & 21,55 & 19,17 & 21,08 & 16,38 & 19,54 & 7,86 \\
\hline Outono & 20,27 & 18,43 & 20,71 & 16,25 & 18,91 & 10,44 \\
\hline Média & $20,60 \mathrm{~A}$ & $18,63 \mathrm{~B}$ & $20,49 \mathrm{~A}$ & $16,09 \mathrm{C}$ & & \\
\hline \multirow[t]{2}{*}{$\mathrm{CV}(\%)$} & 9,45 & 7,89 & 10,08 & 12,13 & & 9,65 \\
\hline & \multicolumn{4}{|c|}{$\operatorname{PBC}(\%)$} & Média & $\mathrm{CV}(\%)$ \\
\hline Inverno & 6,63 & 6,59 & 6,73 & 5,70 & $6,31 b$ & 16,74 \\
\hline Primavera & 9,84 & 7,87 & 8,54 & 6,30 & $8,14 \mathrm{a}$ & 17,95 \\
\hline Verãor & 8,62 & 7,94 & 8,9 & 6,07 & $7,88 \mathrm{a}$ & 18,62 \\
\hline Outono & 7,40 & 7,31 & 7,71 & 6,53 & $7,24 b$ & 20,77 \\
\hline Média & $8,12 \mathrm{~A}$ & $7,43 \mathrm{~A}$ & 7,97A & $6,04 \mathrm{~B}$ & & \\
\hline $\mathrm{CV}(\%)$ & 14,07 & 20,35 & 21,92 & 17,89 & & 19,01 \\
\hline
\end{tabular}

Médias seguidas de letras distintas, maiúsculas na linha e minúsculas na coluna, diferem entre si $(\mathrm{P}<0,05$; teste Tukey). CV=coeficiente de variação.

Os valores de PBF e PBC, no geral, foram mais elevados que os encontrados por Prohman et al. (2004), que trabalharam com coastcross em pastejo com lotação contínua onde encontraram $14,3 \%$ e $6,7 \%$ para PBF e PBC, respectivamente.
Ao comparar o efeito dos tratamentos sobre o FDN da fração lâmina foliar (FDNF), observa-se que a pastagem que não recebeu adubação nitrogenada, apresentou valores mais altos que a pastagem que recebeu a maior dose de adubo e 
era consorciada (Tab. 2). Isso ocorreu porque, nos pastos sem adubação nitrogenada a rebrota não foi tão vigorosa se comparada à das pastagens adubadas, com isso a grande formação de novos tecidos neste último, com consequente formação de células novas, contribuiu para a maior concentração de conteúdo celular se comparado ao conteúdo de parede celular, que é o que determina os teores de FDN.

Tabela 2. Fibra em detergente neutro de lâmina foliar (FDNF) e bainha+colmo (FDNC) da pastagem de coastcross consorciada com amendoim forrageiro, adubadas ou não com $\mathrm{N}$

\begin{tabular}{|c|c|c|c|c|c|c|}
\hline \multirow{2}{*}{ Estação } & CA200 & CA100 & C200 & $\mathrm{CA}$ & \multirow{2}{*}{ Média } & \multirow{2}{*}{$\mathrm{CV}(\%)$} \\
\hline & \multicolumn{4}{|c|}{ FDNF $(\%)$} & & \\
\hline Inverno & 69,17 & 68,57 & 69,09 & 70,20 & 69,26 & 3,24 \\
\hline Primavera & 66,30 & 67,88 & 68,53 & 70,27 & 68,24 & 2,98 \\
\hline Verão & 67,82 & 68,61 & 68,80 & 69,76 & 68,75 & 3,34 \\
\hline Outono & 67,83 & 67,37 & 67,34 & 70,02 & 68,14 & 5,01 \\
\hline Média & $67,78 \mathrm{~B}$ & $68,11 \mathrm{AB}$ & $68,44 \mathrm{AB}$ & $70,07 \mathrm{~A}$ & & \\
\hline \multirow[t]{2}{*}{$\mathrm{CV}(\%)$} & 3,79 & 3,01 & 4,19 & 3,98 & & 3,65 \\
\hline & \multicolumn{4}{|c|}{ FDNC (\%) } & Média & $\mathrm{CV}(\%)$ \\
\hline Inverno & 76,10 & 76,51 & 75,49 & 77,01 & 76,28 & 1,21 \\
\hline Primavera & 75,49 & 75,08 & 75,05 & 76,58 & 75,55 & 3,08 \\
\hline Verão & 75,30 & 76,34 & 75,71 & 76,44 & 75,95 & 3,51 \\
\hline Outono & 76,23 & 75,00 & 75,21 & 77,25 & 75,93 & 4,29 \\
\hline Média & 75,78 & 75,73 & 75,33 & 76,82 & & \\
\hline $\mathrm{CV}(\%)$ & 3,30 & 3,57 & 3,69 & 2,91 & & 3,38 \\
\hline
\end{tabular}

Médias seguidas de letras distintas, na linha, diferem entre si ( $\mathrm{P}<0,05$; teste Tukey). $\mathrm{CV}=$ coeficiente de variação.

A adubação com $\mathrm{N}$ não influenciou a FDN da fração colmo (FDNC). Prohman et al. (2004), ao trabalharem com coastcross, em pastejo com lotação contínua, encontraram valores de FDNF de $65,1 \%$ e FDNC de $74,9 \%$, valores inferiores para a fração folha se comparados aos do presente estudo e semelhantes ao da fração colmo.

Para a DIVMS de lâmina foliar (DIVF) e colmo+bainha (DIVC), não houve diferença quando se compararam os efeitos dos tratamentos na pastagem (Tab. 3). Para DIVF, o período do verão foi o que proporcionou à pastagem melhores condições para que esta tivesse valores mais elevados de DIVF. O inverno foi a estação que apresentou condições desfavoráveis, refletindo em menores valores de DIVF.

Para as plantas inteiras de amendoim forrageiro, os teores de PB (PBA) foram semelhantes aos de PBF do coastcross. Para a PBA, não houve diferença entre as plantas submetidas às diferentes doses de $\mathrm{N}$ (Tab. 4). Na avaliação entre as estações do ano, foram observados maiores valores para a PBA no inverno e menores valores no outono, ficando a primavera e o verão com valores intermediários.
Os teores de FDN de planta inteira de amendoim forrageiro (FDNA) apresentaram interação significativa de tratamento versus época de avaliação, tendo diferenças entre as pastagens submetidas às diferentes doses de $\mathrm{N}$ (Tab. 4). No inverno, o amendoim forrageiro consorciado com a gramínea adubado com $100 \mathrm{~kg}$ de N/ha/ano teve valores de FDNA superiores ao que não recebia adubação. No outono, o FDNA foi maior nas plantas adubadas com a maior dose do adubo e nas não adubadas.

Em relação à DIVMS das plantas de amendoim forrageiro (DIVA), também houve interação significativa entre tratamento e época de avaliação, sendo que na primavera, as plantas de amendoim forrageiro apresentaram valores mais elevados de DIVA quando foram submetidas às maiores doses de N. No outono, o pasto adubado com $100 \mathrm{~kg}$ de N/ha/ano apresentou teores mais elevados de DIVA. Dessa forma, verifica-se que, no período de maior crescimento do pasto, são encontrados valores mais elevados de digestibilidade da forragem, devido ao acelerado ritmo de crescimento a que o pasto é submetido. 
Tabela 3. Digestibilidade in vitro da matéria seca de lâmina foliar (DIVF) e bainha+colmo (DIVC) da pastagem de coastcross consorciada com amendoim forrageiro, adubadas ou não com $\mathrm{N}$

\begin{tabular}{|c|c|c|c|c|c|c|}
\hline \multirow{2}{*}{ Estação } & CA200 & CA100 & $\mathrm{C} 200$ & $\mathrm{CA}$ & \multirow{2}{*}{ Média } & \multirow{2}{*}{$\mathrm{CV}(\%)$} \\
\hline & \multicolumn{4}{|c|}{ DIVF $(\%)$} & & \\
\hline Inverno & 61,59 & 61,54 & 62,54 & 60,31 & $61,5 c$ & 10,07 \\
\hline Primavera & 68,71 & 68,85 & 69,55 & 63,60 & $67,68 b$ & 8,77 \\
\hline Verão & 72,96 & 70,89 & 76,50 & 71,49 & $72,97 \mathrm{a}$ & 8,92 \\
\hline Outono & 64,60 & 62,05 & 63,13 & 61,47 & $62,81 b c$ & 7,25 \\
\hline Média & 66,97 & 65,84 & 67,93 & 64,22 & & \\
\hline \multirow[t]{2}{*}{$\mathrm{CV}(\%)$} & 9,36 & 7,35 & 9,91 & 7,91 & & 8,79 \\
\hline & \multicolumn{4}{|c|}{ DIVC $(\%)$} & Média & $\mathrm{CV}(\%)$ \\
\hline Inverno & 52,96 & 52,15 & 52,9 & 50,37 & $52,10 \mathrm{~b}$ & 6,97 \\
\hline Primavera & 58,46 & 56,09 & 57,16 & 55,61 & $56,83 \mathrm{ab}$ & 9,17 \\
\hline Verão & 59,01 & 58,15 & 56,93 & 56,33 & $57,60 \mathrm{a}$ & 8,30 \\
\hline Outono & 54,08 & 53,77 & 55,25 & 52,56 & $53,91 b$ & 13,94 \\
\hline Média & 56,13 & 55,04 & 55,56 & 53,72 & & \\
\hline $\mathrm{CV}(\%)$ & 11,28 & 9,13 & 9,99 & 10,16 & & 10,14 \\
\hline
\end{tabular}

Médias seguidas de letras distintas, na linha, diferem entre si ( $\mathrm{P}<0,05$; teste Tukey). $\mathrm{CV}=$ coeficiente de variação.

Tabela 4. Valor nutritivo da forrragem da planta inteira de amendoim forrageiro em pastagem consorciada com coastcross, adubadas ou não com $\mathrm{N}$

\begin{tabular}{|c|c|c|c|c|c|}
\hline \multirow{2}{*}{ Estação } & CA200 & CA100 & $\mathrm{C} 200$ & \multirow{2}{*}{ Média } & \multirow{2}{*}{ CV (\%) } \\
\hline & \multicolumn{3}{|c|}{ PB (\%) } & & \\
\hline Inverno & 22,38 & 23,17 & 23,25 & $22,93 a$ & 8,77 \\
\hline Primavera & 18,87 & 18,56 & 18,11 & $18,51 b c$ & 5,54 \\
\hline Verão & 19,75 & 19,83 & 18,90 & $19,50 b$ & 1,96 \\
\hline Outono & 18,34 & 18,14 & 16,39 & $17,62 \mathrm{c}$ & 6,93 \\
\hline Média & 19,84 & 19,93 & 19,16 & & \\
\hline \multirow[t]{2}{*}{$\mathrm{CV}(\%)$} & 7,45 & 5,14 & 5,61 & & 6,21 \\
\hline & \multicolumn{3}{|c|}{ FDN (\%) } & Média & $\mathrm{CV}(\%)$ \\
\hline Inverno & $40,16 \mathrm{ABc}$ & $41,28 \mathrm{Ac}$ & $38,9 \mathrm{Bc}$ & 40,11 & 2,23 \\
\hline Primavera & $43,22 \mathrm{Ab}$ & $43,93 \mathrm{Ab}$ & $43,39 \mathrm{Ab}$ & 43,52 & 2,11 \\
\hline Verão & $47,61 \mathrm{Aa}$ & $47,02 \mathrm{Aa}$ & $48,42 \mathrm{Aa}$ & 47,69 & 3,01 \\
\hline Outono & $43,51 \mathrm{Bb}$ & $46,07 \mathrm{Aa}$ & $46,51 \mathrm{Aa}$ & 45,37 & 3,03 \\
\hline Média & 43,63 & 44,58 & 44,31 & & \\
\hline \multirow[t]{2}{*}{$\mathrm{CV}(\%)$} & 2,61 & 2,07 & 3,33 & & 1,80 \\
\hline & \multicolumn{3}{|c|}{ DIVMS (\%) } & Média & $\mathrm{CV}(\%)$ \\
\hline Inverno & $53,16 \mathrm{Ac}$ & $53,11 \mathrm{Ab}$ & $53,77 \mathrm{Aa}$ & 53,34 & 4,60 \\
\hline Primavera & $60,92 \mathrm{Aa}$ & $52,82 \mathrm{Cb}$ & $57,51 \mathrm{Ba}$ & 57,09 & 3,82 \\
\hline Verão & $50,93 \mathrm{Ac}$ & $52,91 \mathrm{Ab}$ & $55,37 \mathrm{Aa}$ & 53,07 & 7,93 \\
\hline Outono & $57,67 \mathrm{Bb}$ & $63,58 \mathrm{Aa}$ & $58,83 \mathrm{Ba}$ & 60,03 & 3,86 \\
\hline Média & 55,67 & 55,61 & 56,37 & & \\
\hline $\mathrm{CV}(\%)$ & 2,83 & 4,99 & 7,05 & & 5,27 \\
\hline
\end{tabular}

Médias seguidas de letras distintas, maiúsculas na linha e minúsculas na coluna, diferem entre si $(\mathrm{P}<0,05$; teste Tukey). CV=coeficiente de variação.

Os valores de DIVA encontrados foram baixos mesmo o amendoim forrageiro apresentando baixos valores de FDN. Isto se explica pelo fato de a leguminosa conter alta concentração de lignina em sua constituição, o que prejudica a digestibilidade (Euclides et al., 1998). Os valores médios da digestibilidade são mais baixos que os encontrados por Ladeira et al. (2002), que trabalharam com amendoim forrageiro e encontraram valores de 64,4\% de DIVMS.

Os resultados do ganho de peso individual dos animais estão representados na Tab. 5. Não houve efeito dos tratamentos no GMD dos 
animais. Apesar de os valores numéricos serem bem diferentes, a não observância de diferença estatística ocorreu pelo fato de haver grande discrepância dos valores de GMD dos animais em relação à média, elevando o coeficiente de variação dos dados.

Tabela 5. Ganho médio diário GMD (kg/dia) de novilhas criadas em pastagem de coastcross consorciada com amendoim forrageiro, adubadas ou não com $\mathrm{N}$

\begin{tabular}{ccccccc}
\hline Estação & CA200 & CA100 & C200 & CA & Média & CV $(\%)$ \\
\hline Inverno & 0,565 & 0,345 & 0,381 & 0,293 & & \\
Primavera & 0,636 & 0,461 & 0,515 & 0,459 & $0,518 \mathrm{a}$ & 42,10 \\
Verão & 0,435 & 0,583 & 0,499 & 0,544 & $0,515 \mathrm{a}$ & 26,48 \\
Outono & 0,380 & 0,310 & 0,273 & 0,211 & $0,293 \mathrm{~b}$ & 39,05 \\
Média & 0,504 & 0,425 & 0,417 & 0,377 & & \\
CV $(\%)$ & 34,27 & 51,43 & 50,29 & 62,98 & & 49,98 \\
\hline
\end{tabular}

Médias seguidas de letras distintas na coluna diferem entre si ( $\mathrm{P}<0,10$; teste Tukey). $\mathrm{CV}=$ coeficiente de variação.

Em relação a época do ano, o GMD foi mais elevado no verão e na primavera, sendo estas estações semelhantes ao inverno. Este comportamento ocorre porque as pastagens na época das águas possuem maior valor nutritivo e oferecem maior disponibilidade de folhas aos animais, proporcionando a estes um ambiente favorável para que a dieta proporcione alta ingestão de nutrientes com baixo gasto de energia.

A produtividade animal por unidade de área (GPV/ha) apresentou interação significativa entre tratamento e estação do ano. Observa-se que a pastagem que não recebeu adubação apresentou o menor rendimento animal por área na época do inverno, primavera e outono (Tab. 6), sendo que houve interação significativa de tratamento versus época. As pastagens adubadas com $\mathrm{N}$, além de oferecerem maior produtividade $\mathrm{e}$ qualidade, proporcionam ao animal um ambiente pastoril favorável por apresentarem uma estrutura de relvado ideal para a obtenção do alimento no ato do pastejo, pois a quantidade de folhas e o tempo de vida delas fazem com que a forragem ingerida fosse de elevado valor nutritivo.

Tabela 6. Ganho de peso vivo (GPV) de novilhas criadas em pastagem de coastcross consorciada com amendoim forrageiro, adubadas ou não com $\mathrm{N}$

\begin{tabular}{|c|c|c|c|c|c|c|}
\hline \multirow{2}{*}{ Estação } & CA200 & CA100 & C200 & $\mathrm{CA}$ & \multirow{2}{*}{ Média } & \multirow{2}{*}{$\mathrm{CV}(\%)$} \\
\hline & \multicolumn{4}{|c|}{ GPV $(\mathrm{kg} / \mathrm{ha})$} & & \\
\hline Inverno & 289Aab & $152 \mathrm{ABb}$ & $186 \mathrm{ABc}$ & $96 \mathrm{Bb}$ & 181 & 24,19 \\
\hline Primavera & 477Aa & $258 \mathrm{Bb}$ & $401 \mathrm{Ab}$ & $156 \mathrm{Bb}$ & 323 & 11,89 \\
\hline Verão & $455 \mathrm{ABa}$ & $575 \mathrm{Aa}$ & $583 \mathrm{Aa}$ & $365 \mathrm{Ba}$ & 495 & 9,62 \\
\hline Outono & $237 \mathrm{Ab}$ & $206 \mathrm{Ab}$ & $176 \mathrm{Ac}$ & $119 \mathrm{Ab}$ & 185 & 48,90 \\
\hline Total & 1485 & 1191 & 1347 & 735 & & \\
\hline $\mathrm{CV}(\%)$ & 19,81 & 14,68 & 13,12 & 37,4 & & 19,28 \\
\hline
\end{tabular}

Médias seguidas de letras distintas, maiúsculas na linha e minúsculas na coluna, diferem entre si $(\mathrm{P}<0,10 \%$; teste Tukey. CV=coeficiente de variação.

Comparando as épocas do ano, observa-se que no verão obtiveram-se os maiores rendimentos por área nas pastagens submetidas às diferentes doses de $\mathrm{N}$, com exceção do pasto submetido à maior dose de $\mathrm{N}$ e consorciado que obteve resultados semelhantes no inverno, primavera e verão (Tab. 6). O verão proporciona forragem farta e de boa qualidade aos animais por apresentar temperaturas elevadas, fotoperíodo longo, alta precipitação pluvial e ser a época em que o efeito da adubação nitrogenada é transmitido à pastagem, pois a fertilização é realizada na época das águas, iniciando-se na primavera.

Pereira et al. (1996), na Bahia, avaliaram a produção animal por área de Brachiaria humidicula, exclusiva e consorciada com amendoim forrageiro, e obtiveram valores de 475 e $578 \mathrm{~kg}$ de peso vivo/ha/ano para as pastagens exclusivas e consorciadas, respectivamente. A superioridade dos valores verificados para as 
pastagens consorciadas, neste caso, deve-se à não diferenciação de doses de $\mathrm{N}$ entre os tratamentos, entretanto, os resultados obtidos pelo autor ficaram aquém dos encontrados no presente trabalho, com a pastagem consorciada e sem adubação nitrogenada (735kg de PV/ha/ano).

Almeida et al. (2002) observaram que a produção animal em pastos consorciados de Brachiaria decumbens com Stylosanthes guianensis cv. Mineirão encontra-se mais próxima à de pastagens que receberam adubação leve de manutenção.
Quanto à TL, observou-se interação significativa tratamento versus época do ano (Tab. 7), isto é, a pastagem que recebeu $200 \mathrm{~kg}$ de N/ha/ano a TL foi mais alta que a que recebeu $100 \mathrm{~kg}$ de $\mathrm{N} / \mathrm{ha} / \mathrm{ano}$, com exceção do outono. No outono, no pasto consorciado e que recebeu a maior dose de adubo, a TL foi mais elevada que a dos pastos não consorciados e dos pastos consorciados que receberam $100 \mathrm{~kg}$ de fertilizante. Observaram-se, ainda, valores mais baixos de TL nas pastagens que não receberam adubação nitrogenada.

Tabela 7. Taxa de lotação (TL) e número de animais-dia (NAD) de novilhas criadas em pastagem de coastcross consorciada com amendoim forrageiro, adubadas ou não com $\mathrm{N}$

\begin{tabular}{|c|c|c|c|c|c|c|}
\hline \multirow{2}{*}{ Estação } & CA200 & CA100 & C200 & $\mathrm{CA}$ & \multirow{2}{*}{ Média } & \multirow{2}{*}{$\mathrm{CV}(\%)$} \\
\hline & \multicolumn{4}{|c|}{ TL (UA/ha) } & & \\
\hline Inverno & $2,49 \mathrm{Ac}$ & $1,76 \mathrm{Bd}$ & $2,58 \mathrm{Ad}$ & $1,26 \mathrm{Cc}$ & 2,02 & 14,15 \\
\hline Primavera & $6,39 \mathrm{Aa}$ & $3,80 \mathrm{Bc}$ & $6,58 \mathrm{Ab}$ & $2,20 \mathrm{Cb}$ & 4,75 & 12,23 \\
\hline Verão & 7,38Aa & $6,20 \mathrm{Ba}$ & $8,27 \mathrm{Aa}$ & $5,38 \mathrm{Ba}$ & 6,81 & 10,64 \\
\hline Outono & $4,96 \mathrm{Ab}$ & $4,38 \mathrm{Bb}$ & $4,38 \mathrm{Bc}$ & $2,27 \mathrm{Cb}$ & 4,00 & 8,65 \\
\hline Média & 5,31 & 4,04 & 5,45 & 2,77 & & \\
\hline \multirow[t]{2}{*}{$\mathrm{CV}(\%)$} & 11,59 & 7,05 & 13,04 & 11,3 & & 7,74 \\
\hline & \multicolumn{4}{|c|}{ NAD } & Média & $\mathrm{CV}(\%)$ \\
\hline Inverno & 530 & 446 & 535 & 343 & $463 b$ & 30,61 \\
\hline Primavera & 750 & 562 & 795 & 349 & $614 b$ & 18,09 \\
\hline Verão & 1059 & 992 & 1170 & 699 & $980 a$ & 14,67 \\
\hline Outono & 608 & 663 & 643 & 446 & $590 b$ & 11,89 \\
\hline Total & 2947A & $2663 \mathrm{~A}$ & $3143 \mathrm{~A}$ & 1836B & & \\
\hline $\mathrm{CV}(\%)$ & 17,86 & 9,89 & 19,21 & 24,41 & & 16,44 \\
\hline
\end{tabular}

Médias seguidas de letras distintas, maiúsculas na linha e minúsculas na coluna, diferem entre si $(\mathrm{P}<0,5$; teste Tukey). CV=coeficiente de variação.

O verão foi a estação com melhores condições para a manutenção de elevada TL nas pastagens, e seguida pela primavera, sendo esta pelo outono, observando-se valores inferiores no inverno. Isso acontece em pastagens tropicais, pois o verão oferece características ideais para o desenvolvimento das forrageiras.

O NAD foi mais elevado nas pastagens que receberam adubação, demonstrando que o uso de fertilizantes permite que nessa pastagem seja colocado um número maior de animais. Isso faz com que a área utilizada seja menor se comparada com áreas não fertilizadas, podendo uma propriedade ser mais bem aproveitada para outros fins. Este comportamento permite que o ganho por área seja mais elevado, pois o NAD é multiplicado pelo desempenho individual dos animais, resultando no GPV por unidade de área.
Em relação às estações do ano, no verão, foram observados maiores valores de NAD, o que proporcionou maior TL (Tab. 07), consequentemente, maiores valores de GPV (Tab. 06).

\section{CONCLUSÕES}

O valor nutritivo de pastagens consorciadas sem a adição de fertilização nitrogenada é inferior ao das pastagens adubadas, porém, é satisfatório para um bom desempenho animal. A produção animal por área e por animal é prejudicada em pastagens que não recebem nitrogênio por meio de fertilização química, entretanto a consorciação é uma alternativa para a produção de carne, de forma a minimizar a utilização de insumos externos e diminuir os custos de produção. 


\section{REFERÊNCIAS BIBLIOGRÁFICAS}

ALMEIDA, R.G.; NASCIMENTO JUNIOR, D.; EUCLIDES, V.P.B. Produção animal em pastos consorciados sob três taxas de lotação, no cerrado. Rev. Bras. Zootec., v.31, Supl. 2, p.852857,2002

BRENNECKE, K. Efeito de doses de sódio e nitrogênio na composição bromatológica, química e digestibilidade in vitro do capimcoastcross (Cynodon dactylon (L.) Pers.), em duas idades de corte. 2002, 73f. Dissertação (Mestrado) - Faculdade de Zootecnia e Engenharia de Alimentos, Universidade de São Paulo, Pirassununga, SP.

EUCLIDES, V.P.B.; MACEDO, M.C.M.; OLIVEIRA, M.P; Produção de bovinos em pastagens de Brachiaria spp. consorciadas com Calopogonium mucunoides nos cerrados. Rev. Bras. Zootec., v.27, p.238-245, 1998.

GARMAN, C.L.; HOLDEN, L.A.; KANE, H.A. Comparison of in vitro dry matter digestibility of nine feedstufs using three methods of analysis. $J$. Dairy Sci., v.80 suppl.1, p.260, 1997.

GROF, B. Forage attributes of the perennial groundnut Arachis pintoi in a tropical savanna environment in Colombia. In: INTERNATIONAL GRASSLAND CONGRESS, 15., 1985, Kyoto. Proceedings...Kyoto: The Japanese Society of Grassland Science, 1985. p.168-170.

HUGHES, J.C. Short-term variation in animal liveweight and reduction of its effect on weighning. Anim. Breed. Abstr., v.44. p.111-118, 1976.

INSTITUTO AGRONÔMICO DO PARANÁ. Boletim técnico $n^{o} 33$. Londrina, PR, 1999. p.29.

INSTITUTO AGRONÔMICO DO PARANÁ. Cartas climáticas do Estado do Paraná 1994. Londrina, IAPAR, 1994. 49p.

LADEIRA, M.M.; RODRIGUEZ, N.M.; BORGES, I. et al. Avaliação nutricional do feno de Arachis pintoi. 2- Digestibilidade aparente total. In: REUNIÃO ANUAL DA SOCIEDADE BRASILEIRA DE ZOOTECNIA, 39., 2002, Recife. Anais... Recife: SBZ, 2002 (CD-ROM).

MALAVOLTA, E. Elementos de nutrição mineral de plantas. São Paulo: Ceres, 1980. $251 \mathrm{p}$.
MOTT, G.O.; LUCAS, H.L. The design, conduct and interpretation of grazing trials on cultivated and improved pastures. In: INTERNATIONAL GRASSLAND CONGRESS, 6., 1952, Pasadena. Proceedings... Pasadena, 1952. p.1380-1385.

OFFICIAL methods of analysis. Washington: AOAC, 1990. v.1, p.72-74.

PEREIRA, J.M.; SANTANA, J.R.; REZENDE, C.P. Pastagem formada por capim-humidicola (Alternativas para aumentar o porte de nitrogênio em B. humidicola (Rendle) Schweickt). In: REUNIÃO ANUAL DA SOCIEDADE BRASILEIRA DE ZOOTECNIA, 33., 1996, Fortaleza. Anais... Fortaleza: SBZ, 1996. p.3840 .

PEREZ, N.B.; PIZARRO, E. Producción animal en asociaciones gramineas-maní forrajero. In: SEMINARIO DE PASTOS Y FORRAJES, 10., 2006, Maracaibo. Anales... Maracaibo: Universidad del Zulia, 2006. p.109-119.

PROHMAN, P.E.F.; BRANCO, A.F.; JOBIM, C.C. et al. Suplementação de bovinos em pastagem de coastcross (Cynodon dactylon (L.) Pers) no verão. Rev. Bra. Zootec., v.33, p.792800, 2004.

SANTOS, H.G.; JACOMINE, P.K.T.; ANJOS, L.H.C. et al. Sistema brasileiro de classificação de solos. Brasília: CNPS-Embrapa, 1999. 412p.

TILLEY, J.M.A.; TERRY, R.A. A two stage technique for the in vitro digestion of forage crop. J. Br. Grassl. Soc., v.18, p.104-111, 1963.

VAN SOEST, P.J. Nutritional ecology of the ruminant. 2.ed. New York: Cornell University, 1994. 476p.

VAN SOEST, P.J.; ROBERTSON, J.B.; LEWIS, B.A. Methods for dietary fiber, and nonstarch polysaccharides in relation to animal nutrition. $J$. Dairy Sci., v.74, p.3583-3597, 1991.

VILELA, D.; LIMA, J.A.; RESENDE, J.C.; et al. Desempenho de vacas da raça Holandesa em pastagem de coastcross-1. Rev. Bras. Zootec., v.35, p.555-561, 2006. 